Mater. Res. Soc. Symp. Proc. Vol. 1451 (C) 2012 Materials Research Society

DOI: 10.1557/opl.2012.1338

\title{
Growth of Carbon Nanotube Forests on Carbon Fibers with a $\mathrm{SiO}_{2}$ Interlayer
}

Erica F. Antunes ${ }^{2}$, Viviane Q. da Silva ${ }^{1}$, Vagner E. C. Marques ${ }^{1}$, Lilian Siqueira ${ }^{1}$, and Evaldo J. Corat $^{1}$

${ }^{1}$ Laboratório Associado de Sensores e Materiais, Instituto Nacional de Pesquisas Espaciais, CP 515, 12227-010, São José dos Campos, SP, Brasil

${ }^{2}$ Instituto de Ciência e Tecnologia, Universidade Federal de São Paulo, 12231-280, São José dos Campos, SP, Brasil

\section{ABSTRACT}

Ceramic barriers avoid catalyst diffusion to produce better multiwall carbon nanotubes (CNT) on carbon fiber fabrics (CF). We developed a simple method to produce efficiently a silica layer from TEOS pyrolysis at similar conditions of CNT growth from camphor and ferrocene mixtures. This protective layer prevents iron diffusion and allows the vertical alignment of CNTs.

\section{INTRODUCTION}

Nowadays the literature has given special attention in producing laminates with vertically-aligned carbon nanotube (CNT) films among the plies. This is known as "nanostitching". Composites of ceramic fiber fabrics $\left(\mathrm{SiC}, \mathrm{Al}_{2} \mathrm{O}_{3}\right)$ coated with aligned CNTs have shown gains up to $348 \%$ at interlaminar fracture toughness $\left(\mathrm{G}_{\mathrm{IC}}\right)$ [1-4]. Carbon fibers $(\mathrm{CF})$ are more commonly commercialized than the ceramic fibers, but metal diffusion is a critical problem on growing CNTs on CF.

In 2010, our research group published a paper on deposition of amorphous silicon coatings on CF, before depositing vertically-aligned CNTs [5]. Although an efficient way to avoid iron diffusion, the plasma enhanced process used is not easily scalable. Other groups [6,7] have invested efforts in production of ceramic nanocoatings, mainly $\mathrm{Al}_{2} \mathrm{O}_{3}$ and $\mathrm{SiO}_{2}$. Feng and co-workers [6] coated $\mathrm{CF}$ with $\mathrm{Al}_{2} \mathrm{O}_{3}$ from a $0,1 \mathrm{M}$ solution of aluminum nitrate, followed by a heating to $250^{\circ} \mathrm{C}$ at rating of $20 \mathrm{C} / \mathrm{min}$. $\mathrm{Fv}$ and co-workers[7] got a solid $\mathrm{SiO}_{2}$ coating from a hydrolysis, followed by a pyrolysis a solution of toluene with 5 vol.\% tetraethoxy silane and 5 vol.\% silicon tetrachloride.

At current work, we have developed a CF coatind made of amorphous- $\mathrm{SiO}_{2}$ for deposition of vertically-aligned CNT from camphor/ferrocene pyrolysis. We established a simple way to coat the CF fabrics from TEOS pyrolysis, at similar conditions of CNT production. A study of the deposition time of $\mathrm{SiO}_{2}$ layer evaluated the minimal thickness for this layer works as barrier against iron diffusion.

\section{EXPERIMENTAL DETAILS}

The $\mathrm{SiO}_{2}$ layer was deposited on CF surface before CNT growth. Three pieces of the polyacrylonitrile-based CF cloths (Texiglass, CCS200) were simultaneously placed into the 
oven. The reaction happened inside a quartz tube with $4 \mathrm{~cm}$ of internal diameter. Each piece sized $170 \times 35 \mathrm{~mm}$, but the reaction zone measured only $150 \mathrm{~mm}$. The $\mathrm{SiO}_{2}$ deposition was achieved by the decomposition of tetraethyl orthosilicate (TEOS, $\left.\mathrm{Si}\left(\mathrm{OC}_{2} \mathrm{H}_{5}\right)_{4}\right)$ at $700{ }^{\circ} \mathrm{C}$, at selected times $(1,3,5$ and $10 \mathrm{~min})$. Before pyrolysis step, the TEOS bottle was evacuated at $10^{-2}$ Torr, filled with $\mathrm{N}_{2}$, heated at $140^{\circ} \mathrm{C}$, and the vapor was carried to the reaction zone by a $\mathrm{N}_{2}$ flow of 1.5 LPM.

The CNTs grew in the same oven. The CVD process was carried out at atmospheric pressure and at $850{ }^{\circ} \mathrm{C}$. Carbon (camphor, $\mathrm{C}_{10} \mathrm{H}_{16} \mathrm{O}, 84 \%$ of the total mass) and the $\mathrm{Fe}$ catalyst (ferrocene, $\mathrm{Fe}\left(\mathrm{C}_{5} \mathrm{H}_{5}\right)_{2}, 16 \%$ ) sources were evaporated at $200^{\circ} \mathrm{C}$ and carried into the quartz tube by a $\mathrm{N}_{2}$ flow of $1.5 \mathrm{LPM}$. After $5 \mathrm{~min}$ of reaction, the vapors were cut down and the furnace cool down to room temperature under $\mathrm{N}_{2}$ flow.

A JEOL JSM 5610 VPI scanning electron microscope (SEM), and a CM120 transmission electron microscope (TEM) from Philips enabled examining the $\mathrm{SiO}_{2}$ and CNT morphologies. A Fourier transformed infrared spectroscopy (FTIR) equipment from Perkin Elmer, operated at the attenuated total reflectance (ATR) mode, confirmed the presence of amorphous $\mathrm{SiO}_{2}$ coatings. Raman spectra, recorded from 1000 to $3500 \mathrm{~cm}^{-1}$, by using of a Renishaw 2000 system equipped with $\mathrm{Ar}$ laser $(514.5 \mathrm{~nm})$ allowed evaluating the crystalline quality of CNT produced on CF.

\section{RESULTS and DISCUSSION}

Figure 1 shows $\mathrm{SiO}_{2}$ layer deposited on $\mathrm{CF}$ at (a) $1 \mathrm{~min}$, (b) $3 \mathrm{~min}$, (c) $5 \mathrm{~min}$, and (d) 10 min. The macroscopic aspect of $\mathrm{SiO}_{2}$ layers are showed in Fig.1(a1-d1). Notice that all the three CF pieces with the $\mathrm{SiO}_{2}$ layer acquire a homogeneous grey color for all extension of the reaction zone $(15 \mathrm{~cm})$ after $3 \mathrm{~min}$ of deposition. Exhaustive tests were performed until the deposition area to be optimized, mainly about temperature parameter. Temperatures around $850^{\circ} \mathrm{C}$ promotes an excessively reactivity for TEOS decomposition, forming a great quantity of $\mathrm{SiO}_{2}$ nanoparticles in homogeneous phase. Only $3 \mathrm{~cm}$ of deposition extension was achieved at $850^{\circ} \mathrm{C}$, even increasing the $\mathrm{N}_{2}$ flow. Figure 1(a2-d2) shows the morphology of $\mathrm{SiO}_{2}$ surface that covers the fibers without interconnected them. At $10 \mathrm{~min}$ of deposition, a balls-like morphology is dominant. Figure 1(a3-d3) shows an analysis of the thickness of the $\mathrm{SiO}_{2}$ layers. Although only a qualitative inspection has been done, it can be emphasized that the thickness does not follow a linear tendency. However what is truly important is that only $3 \mathrm{~min}$ of pirolysis is enough to cover completely the fiber.

The camphor/ferrocene pyrolysis yields high density aligned multi-walled CNT (MWCNT) forests on CF coated by $\mathrm{SiO}_{2}$ layer. CNTs grow mainly on the surface $\mathrm{CF}$, all around the $\mathrm{CF}$ but mainly pointing up from the cloth surface. Figure 4 shows the typical morphologies of CNTs grown on $\mathrm{SiO}_{2}$ layer deposited at: (a) $1 \mathrm{~min}$, and (b) 3 to $10 \mathrm{~min}$. The time of CNT growth was kept at $5 \mathrm{~min}$ for comparison. Notice that $1 \mathrm{~min}$ of $\mathrm{SiO}_{2}$ deposition is not enough to prevent the iron diffusion and CNTs grows entangled (Figure 2(a1-a2)). The $\mathrm{SiO}_{2}$ layers formed from $3 \mathrm{~min}$ completely block the iron diffusion into $\mathrm{CF}$, and CNTs films can grow verticallyaligned on CF (Figure 2(b1-b2)). The CNT films are $100 \mu \mathrm{m}$ long (Figure 2(b2)), and CNT diameters range from 10 to $80 \mathrm{~nm}$, as shown in the Figure 2c.

Spectroscopic analysis (Raman and FTIR) were performed on CF, SiO2 interlayer and vertically aligned CNTs. Figure 3 a shows FTIR spectra of CF and CF coated by $\mathrm{SiO}_{2}, 1450$ to $750 \mathrm{~cm}^{1}$. The intense silicon-oxygen covalent bonds vibrations appear mainly in the 1200-1000 $\mathrm{cm}^{-1}$ range revealing the existence of a dense silica network, where oxygen atoms play the role of 
bridges between each two silicon sites. The very intense and broad band appearing around 1050 $\mathrm{cm}^{-1}$ and the shoulder around $1200 \mathrm{~cm}^{-1}$ are assigned, respectively to the transversal optical (TO) and longitudinal optical (LO) modes of the $\mathrm{Si}-\mathrm{O}-\mathrm{Si}$ asymmetric stretching vibrations. The symmetric stretching vibrations of Si-O-Si appear at around $790 \mathrm{~cm}^{-1}$. Furthermore, the Si-O inplane stretching vibrations of the silanol $\mathrm{Si}-\mathrm{OH}$ groups appear at around $934 \mathrm{~cm}^{-1}[8-10]$.
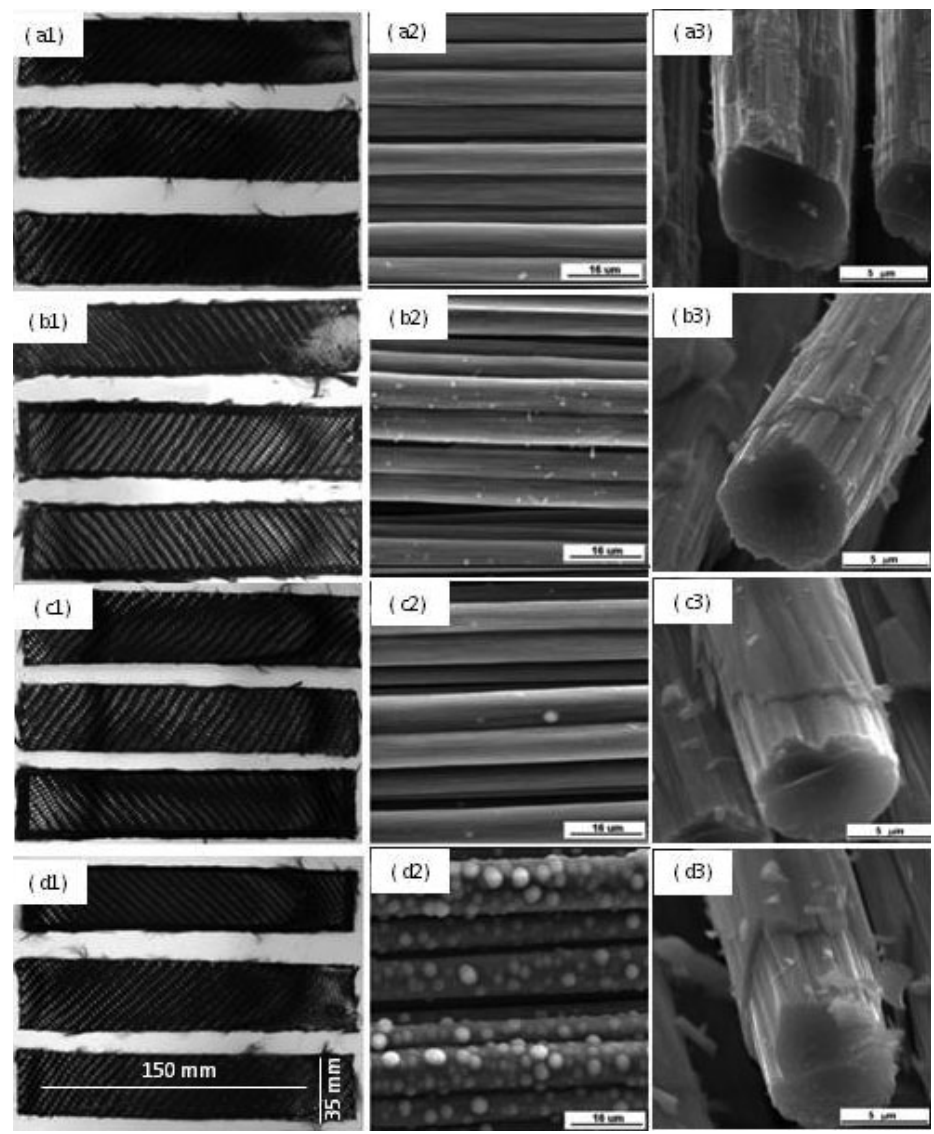

Figure 1: Silica layer deposited on CF at (a) $1 \mathrm{~min}$, (b) $3 \mathrm{~min}$, (c) $5 \mathrm{~min}$, and (d) $10 \mathrm{~min}$. The numbers indicate: (1) photo of the 3 pieces of $\mathrm{CF}$ cloth with $\mathrm{SiO}_{2}$ layer simultaneously deposited; (2) SEM image of $\mathrm{SiO}_{2}$ on CF surface, and (3) the thickness of $\mathrm{SiO}_{2}$ layers 

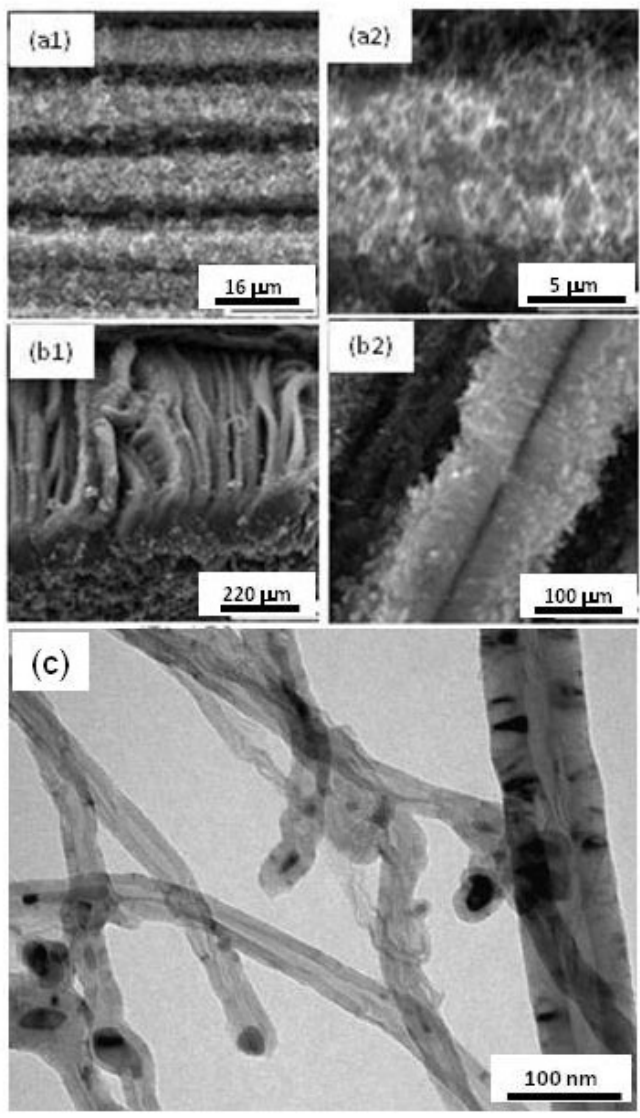

Figure 2: SEM images of typical morphology of CNTs grown at $5 \mathrm{~min}$ on $\mathrm{SiO}_{2}$ layer deposited at: (a) $1 \mathrm{~min}$, and (b) 3 to $10 \mathrm{~min}$; (c) TEM image of internal structure of typical CNT. The numbers ( 1 and 2$)$ indicate images with different magnifications.

The Figure 3(b) shows Raman spectra of CF and CNTs, both graphitic materials. The Raman spectra of graphite-like materials show four main bands: D $\left(\sim 1352 \mathrm{~cm}^{-1}\right), \mathrm{G}\left(\sim 1582 \mathrm{~cm}^{-1}\right)$, D' $\left(\sim 1600 \mathrm{~cm}^{-1}\right)$ and G' $\left(\sim 2700 \mathrm{~cm}^{-1}\right)$, analyzed by Ar laser $(514.5 \mathrm{~nm})$. Usually, the relative intensity between $\mathrm{D}$ and $\mathrm{G}$ bands (ID/IG) indicates the crystalline degree of graphitic materials: as higher is this ratio, more disordered their chemical structure is [11-15]. Raman spectra of CF cloth from Texiglass are typical of PAN based CF, graphitized only to a $1000^{\circ} \mathrm{C}$, which implies 
in a high $\mathrm{I}_{\mathrm{D}} / \mathrm{I}_{\mathrm{G}}$ and $\mathrm{I}_{\mathrm{G}} / \mathrm{I}_{\mathrm{G}} \sim 0$, i. e. a graphitic material with amorphous pattern. On the other hand, spectra with intensity of $\mathrm{G}^{\prime}$ ' band compatible with the intensity of $\mathrm{G}$ band ( $\mathrm{IG}^{\prime} / \mathrm{IG} \sim 1$ or higher) indicate the presence of nanographite. Nanographites are composed or by few graphene sheets, either by turbostratic structures with distances among graphene sheets higher than at single crystals due to the curvature effects [16-18]. Therefore, high intensity $\mathrm{G}^{\prime}$ band is the signature of high quality multi-walled CNT.

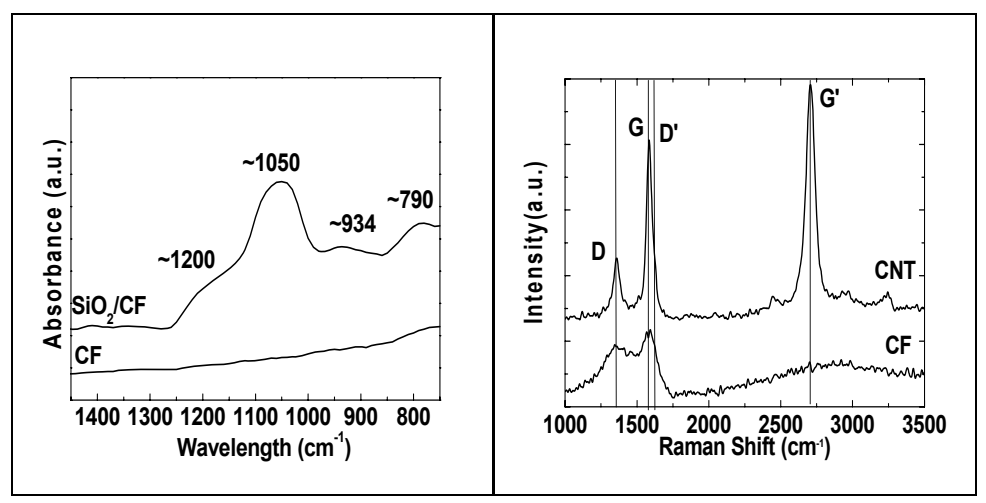

Figure 3: Spectroscopic analyses: (a) FTIR spectra of CF fabric and $\mathrm{SiO}_{2}$ coating; (b) Raman spectra of the CF fabric and vertically aligned CNT film produced on $\mathrm{SiO}_{2}$ layer.

\section{CONCLUSIONS}

There are two advantages of obtaining of $\mathrm{SiO}_{2}$ by TEOS pyrolysis, besides the truly motivation of creating a diffusion barrier against Fe catalyst. The first one is its scalability, since CF cloths are submitted at the similar condition of CNT production. The other one is that the gas phase reactions warranty the formation of fiber coatings without interconnection among them, as occurs when liquid phase impregnation were used. This method also allows the thickness control of $\mathrm{SiO}_{2}$ layer varying the deposition time. Silica depositions run at only 3 min already guarantee an uniform fiber coating, and vertically aligned CNTs on CF are successfully produced.

\section{ACKNOWLEDGMENTS}

We are grateful to the governmental agencies FAPESP and CNPQ for funding our research in Brazil. We also acknowledge Dr. A. A. Martins and Dr A. O Lobo from Universidade do Vale do Paraiba (UNIVAP) for the FTIR measurements. 


\section{REFERENCES}

1. S. S.Wicks, R.G. de Villoria, and B. L.Wardle. Composite Science and Technology, 70, 20$28(2010)$.

2. E. J. Garcia, B. L. Wardle, and A. J. Hart, N. Yamamoto. Composite Science and Technology 68, 2034-2041 (2008).

3. V. P. Veedu, A. Cao, X. Li, K. Ma, C. Soldano, S. Kar, P. M. Ajayan, and M. N. GhasemiNejhad, Nature 5, 457-462 (2006).

4. N. Yamamoto, A. J. Hart, E. J. Garcia, S. S. Wicks, H. M. Duong, A. H. Slocum, and B. L. Wardle. Carbon 47, 551-560 (2009).

5. V. G. de Resende, E. F. Antunes, A. de Oliveira Lobo, D. A. L. Oliveira, V. J. TravaAiroldi, and E. J. Corat, Carbon 48, 3655-3658(2010).

6. F. An, C. Lu, J. Guo, S. He, H. Lu, and Y.Yang. Applied Surface Science 258, 1069-1076 (2011).

7. P. Lv, Yi-y Feng, P.Zhang, H-m Chen, N. Zhao, and W. Feng. Carbon 49, (2011) 46654673.

8. R. Al-Oweini and H. El-Rassy. Journal of Molecular Structure 919, 140-145(2009).

9. N. O. Gopal, K. V. Narasimhulu, and J. L. Rao, Acta Part A 60, 2441-2448(2004).

10. A. Duran, J. M. Fernandez-Navarro, P. Casariego, and A. Joglar, Journal of Non-Crystalline Solids 82, 69-77 (1986).

11. M.S. Dresselhaus, G. Dresselhaus, R. Saito, and A. Jorio, Physics Report 409, 47-99 (2005).

12. A.C. Ferrari, and J. Robertson. Physical Review B 61, 14095-14107 (2000).

13. A.C. Ferrari, and J. Robertson, Physical Review B 64, 075414-1-075414-13(2001).

14. T.W. Ebbesen, and T. Takada, Carbon 33, 973-978(1995).

15. M. J. Matthews, M. A. Pimenta, G. Dresselhaus, and M. Endo, Physical Review B 59, R6585-R6588 (1999).

16. E. F. Antunes, A.O. Lobo, E.J. Corat, and V.J. Trava-Airoldi, Carbon 45, 913-921 (2007).

17. E. B. Barros, A.G. de Souza Filho, H. Son, and M.S. Dresselhaus, Vibrational Spectroscopy 45, 122-127(2007).

18. A.C. Ferrari, J.C. Meyer, V. Scardaci, C. Casiraghi, M. Lazzeri, F. Mauri, S. Piscanec, D. Jiang, K.S. Novoselov, S. Roth, and A.K. Geim, Physical Review Letters 97, 187401-1 187401-4 (2006). 